\title{
Structural and Functional Characterization of Malate Synthase G from Opportunistic Pathogen Pseudomonas aeruginosa
}

\author{
Alyssa C. McVey, ${ }^{\dagger}$ Prasanthi Medarametla, ${ }^{\ddagger}$ Xavier Chee, ${ }^{\S}$ Sean Bartlett, ${ }^{\|}$Antti Poso, ${ }^{\ddagger}, \perp$ \\ David R. Spring, ${ }^{, \oplus \odot}$ Taufiq Rahman, ${ }^{\S \odot}$ and Martin Welch ${ }^{*, \dagger}$ \\ ${ }^{\dagger}$ Department of Biochemistry, University of Cambridge, Cambridge CB2 1QW, U.K. \\ ${ }^{\ddagger}$ School of Pharmacy, University of Eastern Finland, 70211 Kuopio, Finland \\ ${ }^{\S}$ Department of Pharmacology, University of Cambridge, Cambridge CB2 1PD, U.K. \\ "Department of Chemistry, University of Cambridge, Cambridge CB2 1EW, U.K. \\ ${ }^{\perp}$ Department of Internal Medicine VIII, University Hospital Tübingen, 72076 Tübingen, Germany
}

Supporting Information

ABSTRACT: Pseudomonas aeruginosa is an opportunistic human pathogen recognized as a critical threat by the World Health Organization because of the dwindling number of effective therapies available to treat infections. Over the past decade, it has become apparent that the glyoxylate shunt plays a vital role in sustaining $P$. aeruginosa during infection scenarios. The glyoxylate shunt comprises two enzymes: isocitrate lyase and malate synthase isoform G. Inactivation of these enzymes has been reported to abolish the ability of $P$.

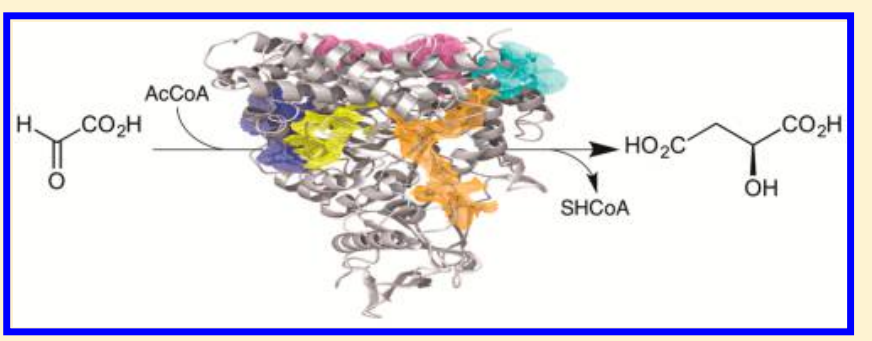
aeruginosa to establish infection in a mammalian model system, yet we still lack the structural information to support drug design efforts. In this work, we describe the first X-ray crystal structure of $P$. aeruginosa malate synthase $G$ in the apo form at $1.62 \AA$ resolution. The enzyme is a monomer composed of four domains and is highly conserved with homologues found in other clinically relevant microorganisms. It is also dependent on $\mathrm{Mg}^{2+}$ for catalysis. Metal ion binding led to a change in the intrinsic fluorescence of the protein, allowing us to quantitate its affinity for $\mathrm{Mg}^{2+}$. We also identified putative drug binding sites in malate synthase $G$ using computational analysis and, because of the high resolution of the experimental data, were further able to characterize its hydration properties. Our data reveal two promising binding pockets in malate synthase $\mathrm{G}$ that may be exploited for drug design.

$\mathrm{M}$ alate synthase isoform G (MS) is the second enzyme of the glyoxylate shunt, which is an anaplerotic pathway that diverts carbon skeletons away from the catabolic reactions of the tricarboxylic acid cycle by providing a route from isocitrate directly to gluconeogenic precursors. ${ }^{1}$ The glyoxylate shunt is present in a wide range of prokaryotic and lower eukaryotic organisms ${ }^{1,2}$ and allows the synthesis of cell constituents from metabolic inputs containing (or metabolized to) a $\mathrm{C}_{2}$ backbone, such as fatty acids, acetate, or ethanol. Instead of undergoing oxidative decarboxylation to yield $\alpha$ ketoglutarate, first isocitrate is cleaved to yield glyoxylate and succinate in a reversible reaction catalyzed by isocitrate lyase (ICL). Thereafter, MS catalyzes the second reaction in the glyoxylate shunt, which is the irreversible condensation of glyoxylate and acetyl-coenzyme A (AcCoA) to yield coenzyme $\mathrm{A}(\mathrm{CoA})$ and malate.

The shunt enzymes have been implicated in virulence, persistence, and antibiotic resistance in several medically relevant organisms, ${ }^{2-5}$ including the opportunistic pathogen Pseudomonas aeruginosa (PA). PA is a Gram-negative bacillus that has been reported to occupy a variety of ecological niches. ${ }^{6}$ It is also a notorious nosocomial pathogen, accounting for $15 \%$ of hospital infections. ${ }^{6-8}$ These infections escalate the need for surgical intervention, increase the overall length and costs of hospitalization, and can carry an average mortality rate of $60 \%$. $\mathrm{PA}$ is also associated with certain types of chronic infection, most notably in the airways of patients with cystic fibrosis. ${ }^{10}$ These infections are often especially difficult to resolve because of the high acquired and intrinsic antibiotic resistance of PA. Certainly, the lack of new anti-Pseudomonal drugs available to the clinical community recently led the World Health Organization to classify PA as a "Priority 1: Critical" pathogen for the development of new antibiotics. ${ }^{11}$

Expression levels of the glyoxylate shunt enzymes are upregulated in chronic PA infections of cystic fibrosis patients. $^{12,13}$ Additionally, ICL and MS appear to be vital for fitness of PA in mammalian infection models. An ICL deletion mutant displayed an increased rate of clearance from the lung and a reduced level of tissue damage in a rat pulmonary infection model. ${ }^{2,14}$ Likewise, a PA double mutant $(\Delta \mathrm{ICL}$

Received: August 30, 2017

Revised: September 25, 2017

Published: October 6, 2017 
$\Delta \mathrm{MS}$ ) was found to be completely avirulent in a mouse pulmonary infection model. ${ }^{15}$ Thus, both ICL and MS are attractive targets for drug discovery because they are essential during infection situations. Crucially, no orthologs of the shunt enzymes exist in humans. ${ }^{4}$ Examination of the crystal structures of shunt enzymes from Mycobacterium tuberculosis (Mtb) suggested that MS would provide a more druggable target than ICL would because of its deeper, more hydrophobic active site, which has to accommodate the pantothenate tail of AcCoA. ${ }^{16,17}$ Moreover, drugs that target the shunt enzymes have potential as broad spectrum antibiotics given their conservation across many pathogenic species. ${ }^{18}$

In this work, we present the $1.62 \AA$ resolution structure of malate synthase $G$ from $P$. aeruginosa. We then use this structural data to identify and describe the most suitable binding pockets for drug development in this critical priority pathogen. Furthermore, we use molecular dynamic simulation to yield the free energy of bound water molecules, mapping the likely physiological hydration network of the protein.

\section{EXPERIMENTAL PROCEDURES}

Cloning, Overexpression, and Purification. MS (GlcB, PA0482) from $P$. aeruginosa strain PAO1 was overexpressed with a Precission protease-cleavable, N-terminal GST tag. A 2 L culture of Escherichia coli strain BL21 containing plasmid [pGEX-6P-1 $(g l c B)]^{19}$ was grown with good aeration at $37{ }^{\circ} \mathrm{C}$ in $2 \times T Y$ medium to an $\mathrm{OD}_{600}$ of 0.6 . The temperature was then decreased to $16{ }^{\circ} \mathrm{C}$; IPTG was added to a final concentration of $0.1 \mathrm{mM}$ to induce expression of the cloned $g l c B$ ORF, and protein expression was continued for a further $16 \mathrm{~h}$. The cells were harvested by centrifugation ( $3430 \mathrm{~g}$ for 30 min at $4{ }^{\circ} \mathrm{C}$ ), and the cell pellets were resuspended in $30 \mathrm{~mL}$ of ice-cold lysis buffer (phosphate-buffered saline supplemented with $1 \mathrm{mM}$ DTT and an EDTA-free protease inhibitor cocktail tablet). The cells were lysed to completion by sonication on ice. Cell debris was removed by centrifugation $(15000 \mathrm{~g}$ for $30 \mathrm{~min}$ at $4{ }^{\circ} \mathrm{C}$ ), and the supernatant was filtered through a $0.45 \mu \mathrm{m}$ membrane filter. Subsequent purification was performed using an ÄKTA FPLC system. The filtered sample was loaded immediately onto a $5 \mathrm{~mL}$ glutathione sepharose column (GSTrapFF) equilibrated with buffer A $[150 \mathrm{mM} \mathrm{NaCl}, 50$ $\mathrm{mM}$ Tris- $\mathrm{HCl}, 1 \mathrm{mM}$ EDTA, and $0.1 \mathrm{mM}$ TCEP (pH 7.5)]. The column was washed with buffer $\mathrm{A}$, and the bound protein was eluted with buffer A supplemented with reduced glutathione $(10 \mathrm{mM})$. Meanwhile, $5 \mathrm{~mL}$ of slurried glutathione Sepharose 4B resin (GE Healthcare) was equilibrated with buffer A in a $50 \mathrm{~mL}$ polypropylene tube. The GST-tagged MS fusion protein was added to the glutathione sepharose beads along with 50 units of PreScission Protease (GE Healthcare). The mixture was then incubated for $48 \mathrm{~h}$ at $4{ }^{\circ} \mathrm{C}$ while being gently mixed to allow cleavage of the fusion protein from the immobilized GST tag. The supernatant was loaded directly onto a 16-600 Superdex 200 preparatory grade column (GE Healthcare) equilibrated with buffer $\mathrm{A}$. The flow rate was 0.8 $\mathrm{mL} \mathrm{min}^{-1}$, and the eluate was collected in $2 \mathrm{~mL}$ fractions. Fractions containing purified MS were pooled, concentrated, frozen in liquid nitrogen, and stored at $-80{ }^{\circ} \mathrm{C}$. The protein concentration was determined by spectrophotometry using the calculated molar extinction coefficient for PA MS $\left(\varepsilon_{\text {calc }}=75985\right.$ $\left.\mathrm{M}^{-1} \mathrm{~cm}^{-1}\right)$.

Preparation of $\mathbf{M g}^{2+}$-Depleted MS. After batch purification, $50 \mathrm{mM}$ EDTA was added to a portion of purified MS to remove bound metals for fluorescence studies. MS was then dialyzed extensively at $4{ }^{\circ} \mathrm{C}$ in $50 \mathrm{mM}$ Tris- $\mathrm{HCl}(\mathrm{pH} 7.5)$ containing $100 \mathrm{mM} \mathrm{NaCl}$ and $10 \mathrm{mM}$ EDTA. The EDTA was then removed by dialysis at $4{ }^{\circ} \mathrm{C}$ against $3 \times 1 \mathrm{~L}$ of $50 \mathrm{mM}$ Tris- $\mathrm{HCl}(\mathrm{pH} 7.5)$ containing $100 \mathrm{mM} \mathrm{NaCl}$. The final protein concentration was adjusted to $175 \mu \mathrm{M}$ after dialysis.

Kinetic Measurements of MS. The enzymatic activity of MS was measured using a modified coupled assay in which the amount of free thiol (present in the reaction product, CoA) was titrated using 5,5'-dithio(2-nitrobenzoic acid) (DTNB). ${ }^{19}$ Briefly, reaction mixtures contained buffer $[50 \mathrm{mM}$ dipotassium phosphate and $15 \mathrm{mM} \mathrm{MgCl}$ ( $\mathrm{pH} 7.5)$ ] supplemented with AcCoA and glyoxylate (as indicated) and $0.2 \mathrm{mM} \mathrm{DTNB}$. The mixture was equilibrated at $37^{\circ} \mathrm{C}$ for $1 \mathrm{~min}$ before the reaction was initiated by addition of MS (final concentration of $25 \mathrm{nM}$ ). The initial linear change in absorbance $(\Delta \mathrm{Abs})$ was recorded at $412 \mathrm{~nm}$ using a Biospectrometer (Eppendorf). Rates were calculated using the molar extinction coefficient of DTNB $\left(14150 \mathrm{M}^{-1} \mathrm{~cm}^{-1}\right)$. Kinetic parameters were calculated from best-fit nonlinear regression using GraphPad Prism version 6.

Crystallization of MS. Crystallization conditions were screened using sitting drop vapor diffusion with $\geq 11 \mathrm{mg} / \mathrm{mL}$ purified protein. The best crystals were obtained with a 1:1 mixture of protein and reservoir solution $[0-25 \mathrm{mM}$ ammonium sulfate, $13-17 \%(\mathrm{v} / \mathrm{v})$ glycerol, and $20-27 \%(\mathrm{w} /$ v) PEG 4000] at $19{ }^{\circ} \mathrm{C}$. Crystals were grown for 2-6 days, treated with a cryoprotectant $[24 \%(\mathrm{v} / \mathrm{v})$ ethylene glycol and $76 \%(\mathrm{v} / \mathrm{v})$ mother liquor], mounted in nylon loops, and flashfrozen in liquid nitrogen prior to data collection.

X-ray Diffraction, Structure Determination, and Refinement. Diffraction data were collected remotely on beamline MX-I03 at the Diamond Light Source Synchrotron (DLS, Didcot, U.K.). Diffraction data were processed using Xia3 DIALS, and the structure was determined by molecular replacement using Phaser. ${ }^{20}$ We used the apo MS structure from Mtb (PDB entry 1N8I) as a model. Automated refinement was performed using PHENIX.refine. ${ }^{21}$ Manual modeling and refinement were performed in COOT. ${ }^{22}$ Data collection and refinement statistics are listed in Table 1.

Fluorimetry. Fluorescence spectra were recorded on a PerkinElmer LS55 luminescence spectrometer using an optical cuvette with a $1 \mathrm{~cm}$ path length. $\mathrm{Mg}^{2+}$-depleted $\mathrm{MS}$ was added to a buffer composed of $50 \mathrm{mM}$ Tris- $\mathrm{HCl}(\mathrm{pH} \mathrm{7.5)}$ and 100 $\mathrm{mM} \mathrm{NaCl}$, giving a final MS concentration of $0.88 \mu \mathrm{M} . \mathrm{MgCl}_{2}$, glyoxylate, and $\mathrm{AcCoA}$ were added to give the final indicated concentrations. The mixtures were equilibrated at $25{ }^{\circ} \mathrm{C}$ for 2 min prior to measurement. An excitation wavelength of $295 \mathrm{~nm}$ was used for measurement of intrinsic tryptophan fluorescence, and the emission spectra were recorded between 300 and 400 $\mathrm{nm}$. The excitation and emission slit widths were $2.5 \mathrm{~nm}$. The data presented are the mean of three independent repeats.

Computational Analysis of MS. The Schrödinger suite (Schrödinger, LLC, New York, NY) was used for all computations. Protein Preparation Wizard with default parameters was used to prepare the MS structure for downstream in silico analyses. ${ }^{23}$ SiteMap was used to predict putative binding pockets. This algorithm predicts binding pockets in proteins on the basis of the geometry, size, volume, and nature (hydrophilicity/hydrophobicity) of amino acid residues. $^{24}$ SiteMap predicts druggable pockets and ranks them using two parameters: the SiteScore and the druggability or "Dscore". SiteScore reveals highly promising binding sites in the protein that can potentially be targeted with drugs, and Dscore indicates the druggability of the predicted site. SiteMap 
Table 1. Summary of Data Collection and Refinement Statistics for P. aeruginosa Malate Synthase G

\begin{tabular}{|c|c|}
\hline \multicolumn{2}{|c|}{ Data Collection ${ }^{a}$} \\
\hline $\mathrm{X}$-ray source & DLS MX-I03 \\
\hline wavelength $(\AA)$ & 0.97625 \\
\hline resolution range $(\AA)$ & $71.17-1.62$ \\
\hline total no. of reflections & $556009(9988)$ \\
\hline no. of unique reflections & $96326(3151)$ \\
\hline multiplicity & $5.8(3.2)$ \\
\hline completeness (\%) & $94.5(69.9)$ \\
\hline mean $I / \sigma(I)$ & $11.75(1.47)$ \\
\hline$R_{\text {sym }}$ & $0.066(0.912)$ \\
\hline$R_{\text {meas }}$ & $0.079(1.080)$ \\
\hline $\mathrm{CC}_{1 / 2}$ & $1(0.5)$ \\
\hline space group & $P 2_{1} 2_{1} 2_{1}$ \\
\hline \multicolumn{2}{|l|}{ unit cell } \\
\hline$a(\AA)$ & 71.17 \\
\hline$b(\AA)$ & 81.2 \\
\hline$c(\AA)$ & 137.57 \\
\hline$\alpha=\beta=\gamma(\operatorname{deg})$ & 90 \\
\hline \multirow{2}{*}{\multicolumn{2}{|c|}{$\begin{array}{l}\text { no. of molecules per asymmetric unit } \\
\text { Refinement }\end{array}$}} \\
\hline & \\
\hline$R_{\text {work }}(\%)$ & 16.7 \\
\hline$R_{\text {free }}(\%)$ & 19.6 \\
\hline \multicolumn{2}{|l|}{ no. of atoms } \\
\hline protein & 6350 \\
\hline glycerol & 4 \\
\hline 1,2-ethanediol & 15 \\
\hline ions & 2 \\
\hline water & 691 \\
\hline \multicolumn{2}{|l|}{ root-mean-square deviation } \\
\hline bond lengths $(\AA)$ & 0.0008 \\
\hline bond angles (deg) & 0.897 \\
\hline Wilson $B$ factor $\left(\AA^{2}\right)$ & 19.6 \\
\hline \multicolumn{2}{|l|}{ average $B$ factor $\left(\AA^{2}\right)$} \\
\hline overall & 27.30 \\
\hline protein & 25.49 \\
\hline glycerol & 56.28 \\
\hline 1,2-ethanediol & 60.92 \\
\hline ions & 54.90 \\
\hline water & 38.76 \\
\hline \multicolumn{2}{|l|}{ Ramachandran analysis (\%) } \\
\hline favored & 98 \\
\hline allowed & 1.9 \\
\hline outliers & 0.1 \\
\hline rotamer outliers & 0.3 \\
\hline MolProbity Clashscore & 5 \\
\hline PDB entry & 5OAS \\
\hline
\end{tabular}

${ }^{a}$ Values for the highest-resolution shell are given in parentheses.

was run using a fine grid option with a more restrictive definition of hydrophobicity to exclude solvent-exposed regions during binding site prediction.

The solvation network plays an important role in determining protein-ligand binding affinity and may be useful when designing or conducting virtual screening of potential inhibitors. Probable hydration sites and associated thermodynamic properties were predicted using the WaterMap module. ${ }^{25}$ WaterMap predicts hydration sites and their properties in user-defined regions on the basis of molecular dynamics. WaterMap was run using default parameters to understand the druggability of MS through its solvation network.

\section{RESULTS AND DISCUSSION}

Kinetic Analysis. Purified PA MS exhibited MichaelisMenten kinetics for glyoxylate and AcCoA substrates (Figure $1)$. The relevant steady state kinetic parameters are listed in

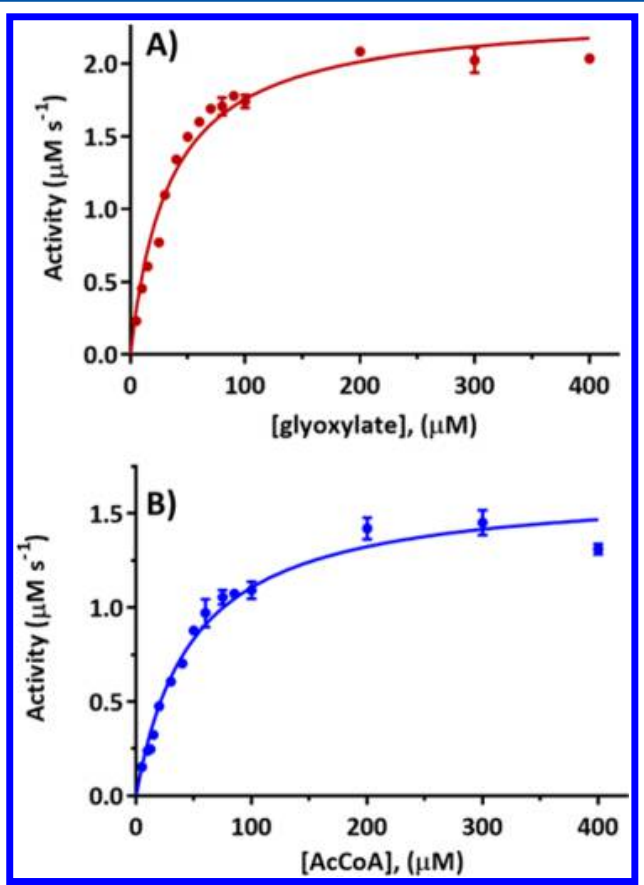

Figure 1. Michaelis-Menten kinetics of $P$. aeruginosa malate synthase G. Enzyme activity was measured by fixing the concentration of one substrate [either AcCoA (A) or glyoxylate (B)] at $0.2 \mathrm{mM}$ and varying the concentration of the second substrate as indicated. Each assay was performed in triplicate. Error bars correspond to \pm 1 standard deviation.

Table 2. Comparison of Kinetic Parameters of MS from Other Microorganisms

\begin{tabular}{lcccc}
\multicolumn{1}{c}{ organism } & $\begin{array}{c}K_{\mathrm{m}, \mathrm{gly}} \\
(\mu \mathrm{M})\end{array}$ & $\begin{array}{c}K_{\mathrm{m}, \mathrm{AcCOA}} \\
(\mu \mathrm{M})\end{array}$ & $\begin{array}{c}V_{\mathrm{max}} \\
\left(\mu \mathrm{mol} \mathrm{mg}^{-1} \mathrm{~s}^{-1}\right)\end{array}$ & ref \\
P. aeruginosa & 34 & 47 & 1200 & this work \\
P. aeruginosa & 70 & 12 & 990 & 19 \\
M. tuberculosis & 30 & 10 & $23\left(k_{\mathrm{cat}}\right)$ & 28 \\
M. tuberculosis & 57 & 30 & 360 & 26 \\
E. coli & 21 & 9 & 2160 & 27 \\
C. glutamicum & 30 & 12 & - & 29 \\
\hline
\end{tabular}

Table 2. Kinetic analysis of purified PA MS has been performed in just one study, which reported a lower substrate affinity for glyoxylate and a higher substrate affinity for AcCoA. ${ }^{19}$ Results from kinetic analyses of other MSs from Mtb, E. coli, and Corynebacterium glutamicum were comparable (Table 2). ${ }^{26-28}$ Additionally, Roucourt et al. ${ }^{19}$ have determined that the PA MS enzymatic reaction proceeds through a sequential mechanism, as opposed to a substituted mechanism.

Amino Acid Sequence Alignment. We aligned MS amino acid sequences sourced from the Uniprot database $(P$. aeruginosa, Q9I636; E. coli, P37330; M. tuberculosis, P9WK17; 


\begin{tabular}{|c|c|}
\hline $\begin{array}{l}\text { zulosis_/1-7. } \\
/ / 1-731\end{array}$ & 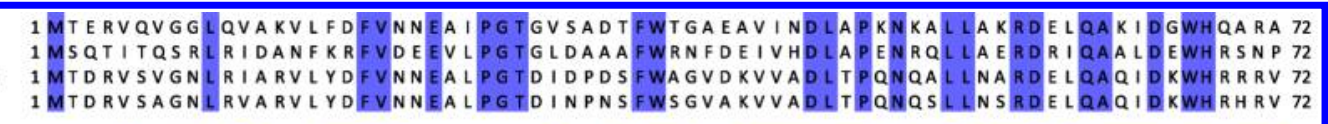 \\
\hline 25 & 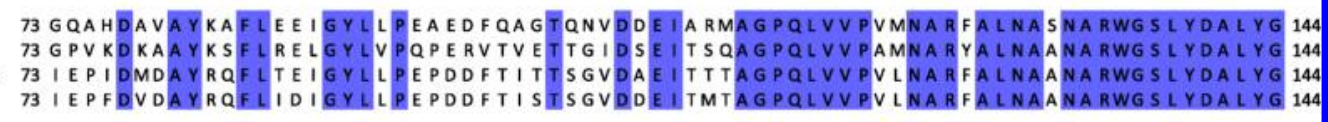 \\
\hline-725 & 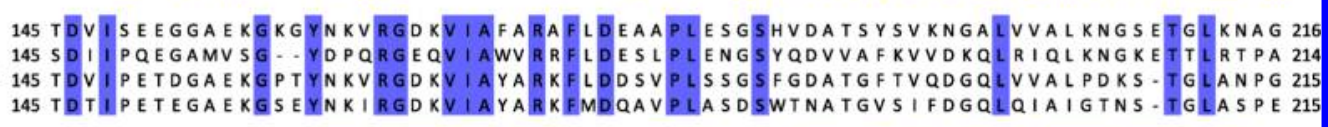 \\
\hline 125 & 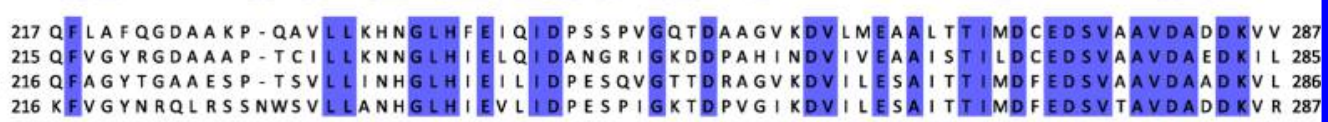 \\
\hline 25 & 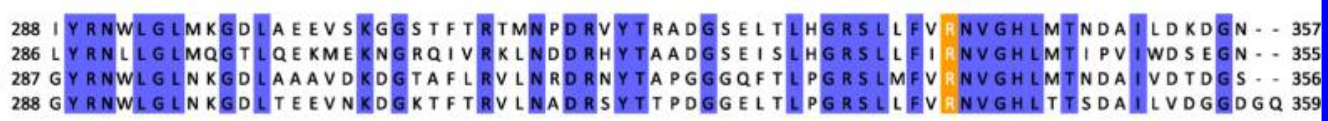 \\
\hline 1-741 & 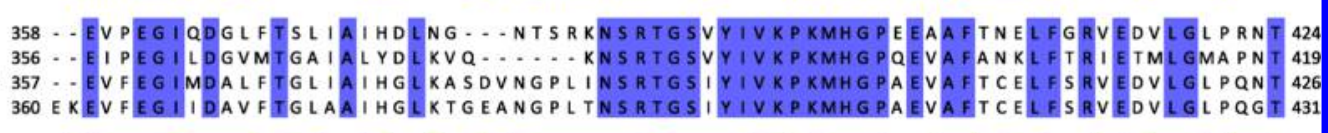 \\
\hline-741 & 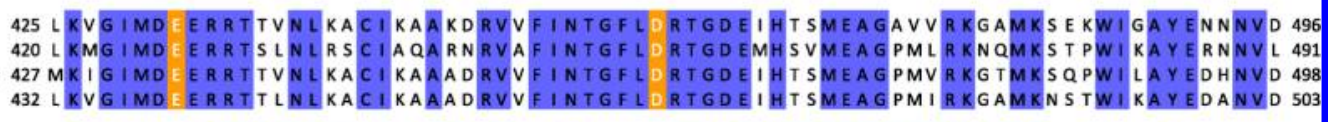 \\
\hline-741 & $\begin{array}{l}497 V G L A T \\
492 \text { S GLF C } \\
499 \text { A GLA A } \\
504 \text { I GLA A }\end{array}$ \\
\hline & 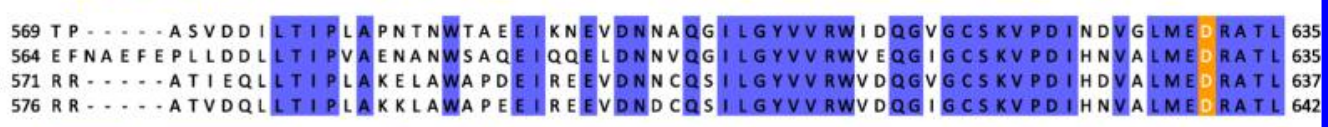 \\
\hline 11 & 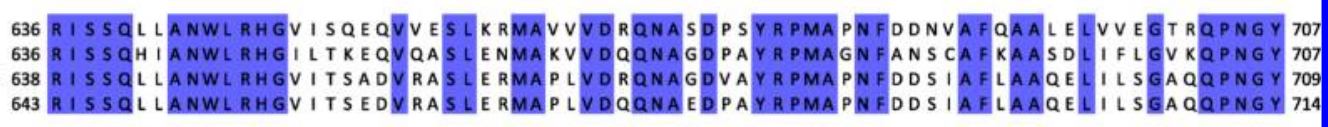 \\
\hline 1 & $\begin{array}{l}708 \text { TEPVLHRRRREFKAKNG } \\
708 \text { TEPLLHAWRLREKESH. } \\
710 \text { TEP L LRRRREFKARAA } \\
715 \text { TEPILHRRRREFKAQNR. }\end{array}$ \\
\hline
\end{tabular}

Figure 2. Amino acid sequence alignment of $P$. aeruginosa malate synthase $\mathrm{G}$ with homologues whose structures have been determined by $\mathrm{X}$-ray crystallography: E. coli, P37330, PDB entry 1P7T; M. tuberculosis, P9WK17, PDB entry 1N8I; M. leprae, O32913, PDB entry 4EX4. Amino acids are colored by sequence identity, where regions of $100 \%$ sequence identity are highlighted in purple. Amino acids known to be involved in catalysis in $E$. coli and M. tuberculosis are highlighted in orange; these are conserved among all four organisms shown.

Mycobacterium leprae, O32913) with Clustal Omega ${ }^{30,31}$ and displayed the alignment with Jalview ${ }^{32}$ (Figure 2). There is $60 \%$ sequence identity between PA and E. coli MS and 70\% sequence identity between PA and Mtb MS. The amino acid residues that are identical among all four species are highlighted in purple, and the residues known to be involved in catalysis in $\mathrm{Mtb}$ and E. coli are highlighted in orange. ${ }^{26-28,33} \mathrm{We}$ also compared amino acid identity within a larger group of pathogenic organisms that encode MS, signifying the evolutionary relationship of MS in other medically relevant organisms (Figures S1 and S2).

Tertiary Structure of MS. We crystallized PA MS and determined the three-dimensional structure by molecular replacement using Mtb MS (PDB entry $1 \mathrm{~N} 8 \mathrm{I}$ ) as a template. PA MS crystallized with one molecule in the asymmetric unit. Consistent with this, MS also behaved as a monomer in solution (Figure S3). The model (Figure 3) was optimized with an $R_{\text {work }}$ of $16.7 \%$ and an $R_{\text {free }}$ of $19.6 \%$. The Ramachandran distribution of all amino acid residue dihedral angles in the protein structure indicates that $98 \%$ of the amino acids are in favored or allowed regions (Figure S4). The structure of MS in the apo, substrate-bound, or product-bound form from three

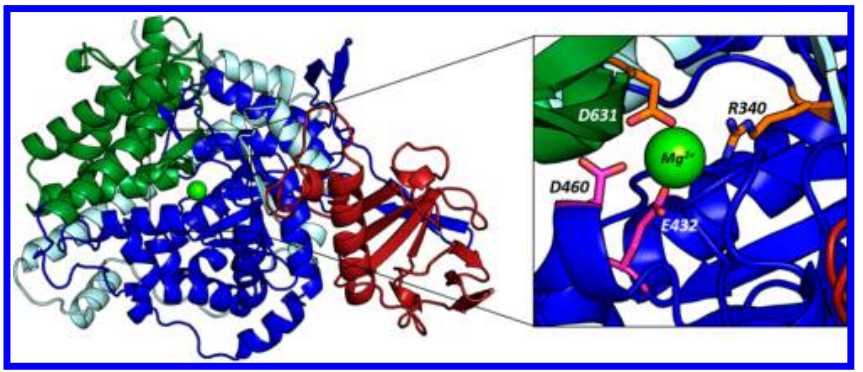

Figure 3. Cartoon representation of malate synthase G from $P$. aeruginosa (PDB entry 5OAS). The TIM barrel, $\alpha$-helical, and $\beta$-sheetrich domains are colored blue, green, and red, respectively. The $\mathrm{N}$ terminus (amino acids 2-115) is colored light cyan. A closer look at the active site shows the proposed substrate binding residues, Glu432 and Asp460, depicted as magenta sticks and the proposed catalytic residues, Asp631 and Arg340, shown as orange sticks. The residues involved in catalysis are oriented around a $\mathrm{Mg}^{2+}$ ion, which is depicted as a chartreuse sphere.

other prokaryotic species has been elucidated by X-ray crystallography: E. coli (PDB entries 1P7T and 2JQX), Mtb (PDB entries 1N8W, 1N8I, and 2GQ3), and M. leprae (PDB 
entry 4EX4). In addition, while our manuscript was in preparation, we became aware that a structure of $P$. aeruginosa MS with glyoxylate bound in the active site had been deposited in the PDB (entry 5VFB). However, to the best of our knowledge, this structure has not yet been described in the literature. In common with these previously reported MS structures, PA MS is composed of three domains: a TIM barrel domain with eight $\alpha$-helices and eight $\beta$-strands (amino acids 116-135 and 266-589), a helical domain (amino acids 590725 ), and a $\beta$-sheet-rich domain (amino acids 136-265) inserted between the first $\alpha$-helix and second $\beta$-sheet of the TIM barrel domain. Near the $\mathrm{N}$-terminus of the protein is a strikingly long $\alpha$-helix (amino acids 32-71) that partially wraps around the TIM barrel domain (Figure 3 ).

Comparison of the structure presented here with known structures of MS from other organisms revealed that the active site residues and the $\mathrm{Mg}^{2+}$ ion are highly conserved across species. $^{26,27,33-37}$ For example, the backbone rmsd of the superposition between the Mtb MS used as the molecular replacement template (PDB entry $1 \mathrm{~N} 8 \mathrm{I}$ ) and PA MS is $0.94 \AA$ over $682 \mathrm{C} \alpha$ atoms, and among the active site residues, the rmsd is $0.20 \AA$. The active site sits between the TIM barrel and a loop (amino acids 615-631 in PA) from domain II, and the known active site residues are present in the PA MS structure in the same positions (not shown). The active sites compared between apo and substrate-bound crystal structures of MS are practically identical, except for the tightening of the aforementioned loop from domain II when glyoxylate is bound (not shown), so MS is generally not considered to undergo major conformational changes during catalysis. ${ }^{35}$ Additionally, comparison of the apo structure presented here with the glyoxylate-bound structure of PA MS recently deposited in the PDB (entry 5VFB) revealed no conformational differences except for a small shift in the solvent-exposed loop (amino acids 305-312) far from the active site.

Influence of $\mathrm{Mg}^{2+}$ on Substrate Binding and the Active Site Environment. The PA MS crystal structure revealed electron density in the $F_{0}-F_{c}$ difference map for a $\mathrm{Mg}^{2+}$ ion and a molecule of ethylene glycol (EDO), the cryoprotectant used when mounting MS crystals, in the active site. $\mathrm{Mg}^{2+}$ is reportedly essential for the enzymatic function of MS and is present in every MS crystal structure published. In these other structures, the $\mathrm{Mg}^{2+}$ is coordinated by four water molecules and conserved Glu and Asp residues in an octahedral conformation. $^{26,27,35,36,38,39}$ However, in our structure, the $\mathrm{Mg}^{2+}$ appears to be coordinated by the EDO molecule, one water molecule, and the side chains of Glu432, Asp460, Glu274, and Asp275 (Figure 4). These amino acids contain carboxylate groups, all located within $3.5 \AA$ of the metal ion, and could be interacting to decrease the overall energy. We also observed a nearby conserved tryptophan residue (Trp539 in our structure), which could be used as a fluorescent reporter to monitor metal ion binding in the active site. To test this, we measured the intrinsic tryptophan fluorescence of PA MS to quantify the binding affinity of $\mathrm{Mg}^{2+}$ and to examine the effect of the substrate(s) on $\mathrm{Mg}^{2+}$ binding.

To investigate the $\mathrm{Mg}^{2+}$ binding properties of PA MS, we first removed any prebound $\mathrm{Mg}^{2+}$ from the purified protein. We observed a change in relative tryptophan fluorescence intensity and $\lambda_{\max }$ upon addition of $\mathrm{Mg}^{2+}$ and substrates to demetallized MS. We determined $\lambda_{\max }$ for demetallized MS as $340 \mathrm{~nm}$, which was red-shifted to $342 \mathrm{~nm}$ upon addition of $10 \mathrm{mM} \mathrm{MgCl}_{2}$ (Figure 5A). This indicates that the environment around the

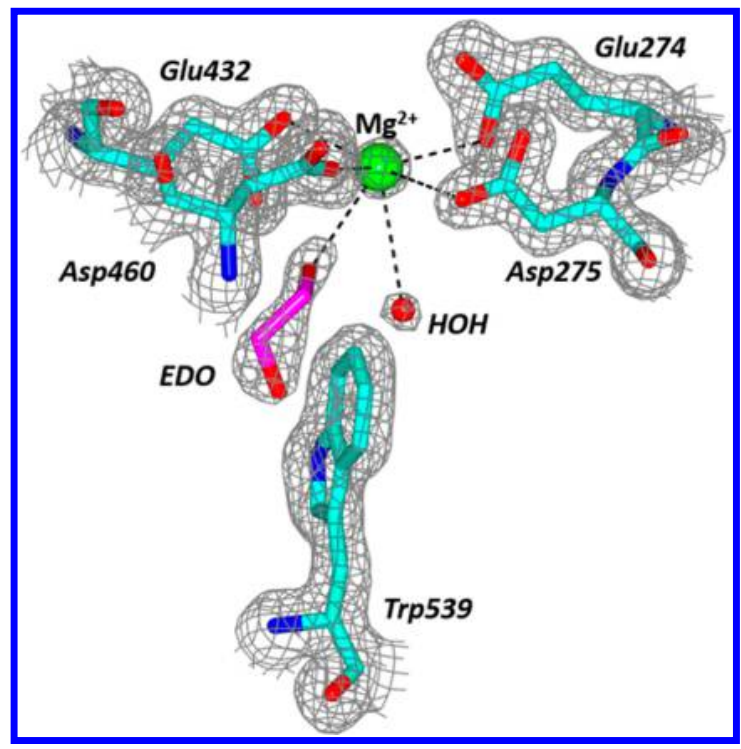

Figure 4. $\mathrm{Mg}^{2+}$ is coordinated by Glu274, Asp275, Glu432, Asp460, ethylene glycol (EDO), and a single water molecule in the active site of $P$. aeruginosa malate synthase G. The electron density map is contoured at $1.5 \sigma$. Trp539 is located $\sim 6 \AA$ from the $\mathrm{Mg}^{2+}$ in the crystal structure (PDB entry 5OAS).

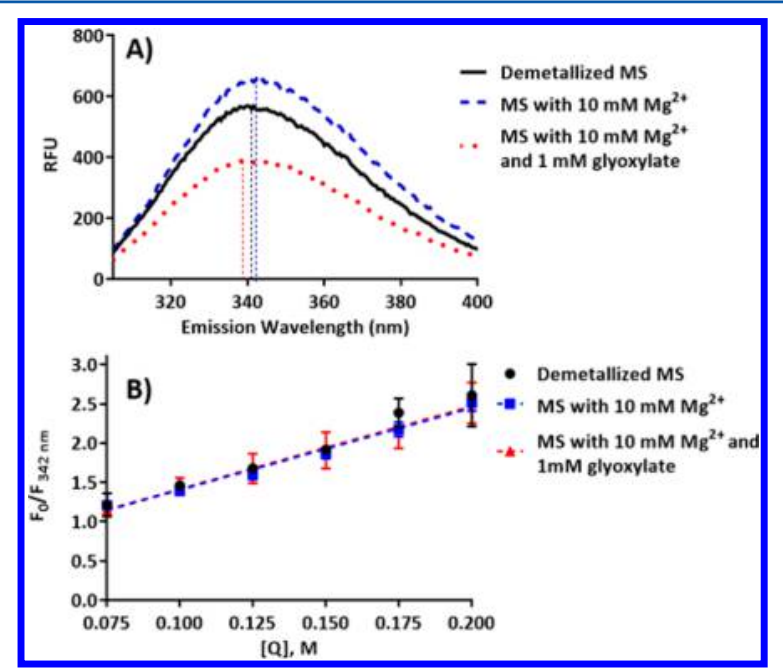

Figure 5. (A) Fluorescence spectra of demetallized malate synthase $G$ (black line), demetallized malate synthase $\mathrm{G}$ with $10 \mathrm{mM} \mathrm{Mg}{ }^{2+}$ added (blue dashes), and demetallized malate synthase $\mathrm{G}$ with $10 \mathrm{mM} \mathrm{Mg}{ }^{2+}$ and $1 \mathrm{mM}$ glyoxylate added (red dots). The $\lambda_{\max }$ for each spectrum is indicated by a vertical dashed line of the corresponding color. (B) Stern-Volmer analyses indicate no global conformational changes as a result of binding of $\mathrm{Mg}^{2+}$ or glyoxylate to malate synthase G. Error bars correspond to \pm 1 standard deviation.

tryptophan residue(s) becomes more hydrophilic and solventexposed in the presence of $\mathrm{Mg}^{2+}$. Conversely, $\lambda_{\max }$ was blueshifted to $337 \mathrm{~nm}$ after the addition of $1 \mathrm{mM}$ glyoxylate (in the presence of $10 \mathrm{mM} \mathrm{MgCl}$ ), indicating that the environment around Trp539 becomes more hydrophobic and less exposed to the bulk solvent. However, when $1 \mathrm{mM}$ glyoxylate was added to demetallized MS in the absence of added $\mathrm{Mg}^{2+}$, there was no deviation in $\lambda_{\max }$ or fluorescence intensity compared with the spectrum of the demetallized protein alone, implying that $\mathrm{Mg}^{2+}$ is needed in the active site for glyoxylate to bind (Figure S5A).

Interestingly, a comparison of the structure described here with that of PA MS with bound glyoxylate (PDB entry 5VFB) 
reveals no apparent conformational differences between the active sites. Together with the results outlined here, this is consistent with physical occlusion of the bulk solvent in the active site by the substrate. To establish whether binding of $\mathrm{Mg}^{2+}$ or glyoxylate to PA MS is accompanied by global conformational changes, we measured the accessibility of the tryptophan residues to an extrinsic neutral quencher, acrylamide. The presence of increasing concentrations of acrylamide caused progressively stronger quenching of tryptophan fluorescence, but the apparent dynamic quenching constant $\left(K_{\mathrm{SV}}=10.5 \pm 0.2 \mathrm{M}^{-1}\right)$ was similar for demetallized MS and for $\mathrm{Mg}^{2+}$-bound or glyoxylate-bound MS (Figure 5B). This indicates that the changes in tryptophan fluorescence arising from $\mathrm{Mg}^{2+}$ or glyoxylate binding arise as a consequence of changes in the local microenvironment of one or more Trp residues, most likely $\operatorname{Trp} 539$, in the active site. We also examined whether the secondary structure content of the protein was altered in the presence of its substrates using circular dichroism (Figure S6). In contrast to a previous study, we found no apparent changes in ellipticity upon addition of the substrates to native MS. ${ }^{40}$

Adding AcCoA to demetallized MS prior to $\mathrm{Mg}^{2+}$ or glyoxylate yielded no change in fluorescence intensity or $\lambda_{\max }$ (Figure S5B). However, when a saturating concentration of AcCoA was added after $\mathrm{Mg}^{2+}$ and glyoxylate, the spectrum recovered to that of the $\mathrm{Mg}^{2+}$-bound spectrum. This is consistent with a sequential reaction mechanism in which glyoxylate binding is a prerequisite for acetyl-CoA binding, and that $\mathrm{Mg}^{2+}$ remains bound in the active site upon release of the reaction products. ${ }^{19,26-29,34,38-40}$

The enhancement in MS tryptophan fluorescence following addition of $\mathrm{Mg}^{2+}$ suggested that this spectroscopic signal might be used quantitatively to measure binding of $\mathrm{Mg}^{2+}$ to the enzyme. PA MS tryptophan fluorescence increased hyperbolically with an increase in $\mathrm{Mg}^{2+}$ concentration, as is typical of a saturable binding system (Figure 6A). In the presence of glyoxylate, the same $\mathrm{Mg}^{2+}$ titration also yielded a binding isotherm, except that increasing $\mathrm{Mg}^{2+}$ concentrations led to saturable quenching of fluorescence (Figure 6A). Scatchard analysis of the fluorescence data yielded apparent $K_{\mathrm{d}}$ values for the $\mathrm{Mg}^{2+}-\mathrm{MS}$ complex of 525 and $653 \mu \mathrm{M}$ in the absence and

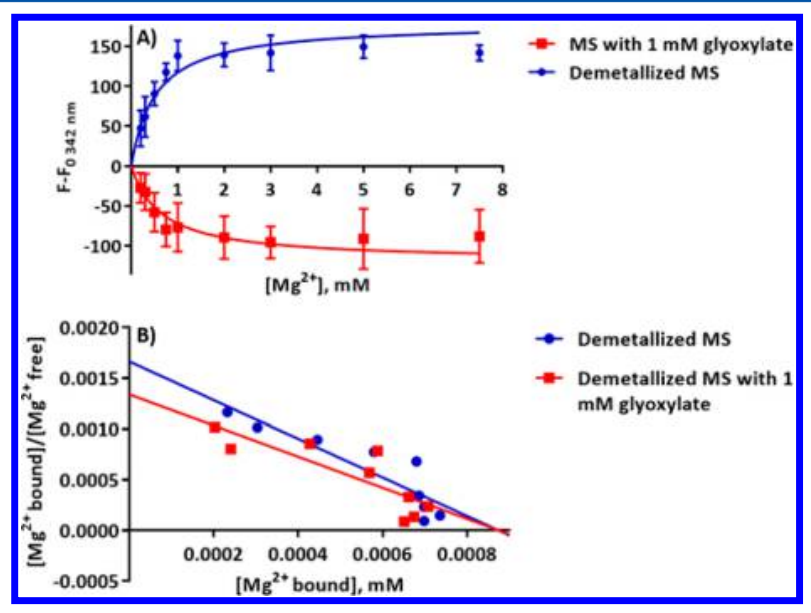

Figure 6. (A) $\mathrm{Mg}^{2+}$ binding curves in the presence (red) and absence (blue) of $1 \mathrm{mM}$ glyoxylate. Note that glyoxylate quenches the tryptophan fluorescence of $P$. aeruginosa malate synthase $G$ in the presence of $\mathrm{Mg}^{2+}$. Error bars correspond to \pm 1 standard deviation. (B) Scatchard analysis of $\mathrm{Mg}^{2+}$ binding data. presence of glyoxylate, respectively (Figure 6B). This is comparable with the binding affinity of $\mathrm{Mg}^{2+}$ for other enzymes. $^{41}$

On the basis of sequence and structural similarity, we propose that the amino acid residues involved in catalysis in PA MS are Arg340, Glu432, Asp460, and Asp631 (Figures 2 and $3)$. We propose a mechanism, consistent with our fluorescence data and previous studies on MS in Mtb and E. coli, ${ }^{26-28,33}$ in which $\mathrm{Mg}^{2+}$ is coordinated in an octahedral conformation by the carboxylate side chains of Glu432 and Asp460, along with four water molecules. ${ }^{39}$ In this model (Figure S7), glyoxylate enters the active site and displaces two of the water molecules in the $\mathrm{Mg}^{2+}$ coordination sphere. Following this, AcCoA enters the active site. Asp631 then deprotonates AcCoA. ${ }^{38}$ The resulting enolate attacks glyoxylate (activated by chelation of $\mathrm{Mg}^{2+}$ ) to form a malyl-CoA intermediate that, in turn, deprotonates a proximal water molecule. This affords a hydroxide anion that can attack and hydrolyze the thioester. Arg340 then acts as a catalytic acid, protonating CoA, which causes CoA to leave the active site first, followed by malate. ${ }^{28}$

Identification of Potential Binding Sites in PA MS. Because PA is such a high-priority pathogen for new antibiotic discovery efforts, we wanted to identify any potential binding sites in PA MS that might facilitate structure-based drug design. Therefore, we analyzed the PA MS crystal structure using Schrödinger's SiteMap. We denoted the five top-ranking potential binding sites identified by SiteMap as A-E, and their SiteMap parameters are listed in Table 3. The location of each site on the crystal structure is shown in Figure $7 \mathrm{~A}$ as colored mesh (site A, yellow; site B, orange; site C, magenta; site $\mathrm{D}$, blue; site $\mathrm{E}$, cyan). Sites A-E possess a SiteScore of $>0.80$, which is the minimum recommended value to distinguish between a drug binding and non-drug binding site. $^{24}$ Site $\mathrm{A}$ is the top-ranked potential binding site with a SiteScore of 1.10 and a Dscore of 1.16. Site B is second-ranked with a SiteScore of 0.99 and a Dscore of 1.02 .

These scores are consistent with those from earlier studies in proteins in which drugs that bind with submicromolar affinity have been identified, ${ }^{24}$ indicating that sites $A$ and $B$ are promising binding sites that could be used for structure-driven drug design. Site A (Figure 7B) is narrow and highly hydrophobic in nature, with a hydrophobic-to-hydrophilic character ratio of 2.22 . For reference, the mean hydrophobicto-hydrophilic ratio for tight binding sites in proteins is $1.60 .^{24}$ This ratio, along with the SiteScore and Dscores calculated by SiteMap, implies that this pocket is suitable for exploration using druglike molecules. Also, because the pocket is located deep within the protein, small molecules could be accommodated, rather than larger ones, whose entry may be hindered. Site $B$ has the largest predicted volume $\left(569 \AA^{3}\right)$ and spreads over the entrance of the active site. Site B has a hydrophobic interior region and a hydrophilic exterior, with a hydrophobicto-hydrophilic character ratio of 0.61 . The residues in site B are displayed in Figure 7C.

Having identified potential ligand binding sites in PA MS, we assessed the likely impact on enzyme function of binding of the drug to these sites, and their degree of conservation across species (including $\mathrm{Mtb}, \mathrm{PDB}$ entry $5 \mathrm{CC} 5$; E. coli, PDB entry 1P7T; and M. leprae, PDB entry 4EX4). The protein structure alignment revealed that site $B$ incorporates the known substrate binding sites of MS (Figure 8) and contains two of the residues involved in catalysis in PA, Arg340 and Aps631, and the active site fluorophore, Trp539 (Figure 7C). Site A also partially 
Table 3. SiteMap Parameters for Predicted Binding Sites A-E

\begin{tabular}{cccccc} 
site & SiteScore & size (no. of site points) & Dscore & volume $\left(\AA^{3}\right)$ & hydrophobic \\
site A & 1.10 & 123 & 1.16 & 475.01 & 0.72 \\
site B & 0.99 & 188 & 1.02 & 569.03 & 0.58 \\
site C & 0.97 & 163 & 1.02 & 461.24 & 0.59 \\
site D & 0.96 & 110 & 0.97 & 269.12 & 0.89 \\
site E & 0.87 & 80 & 0.87 & 1.06 & 0.50 \\
\hline
\end{tabular}

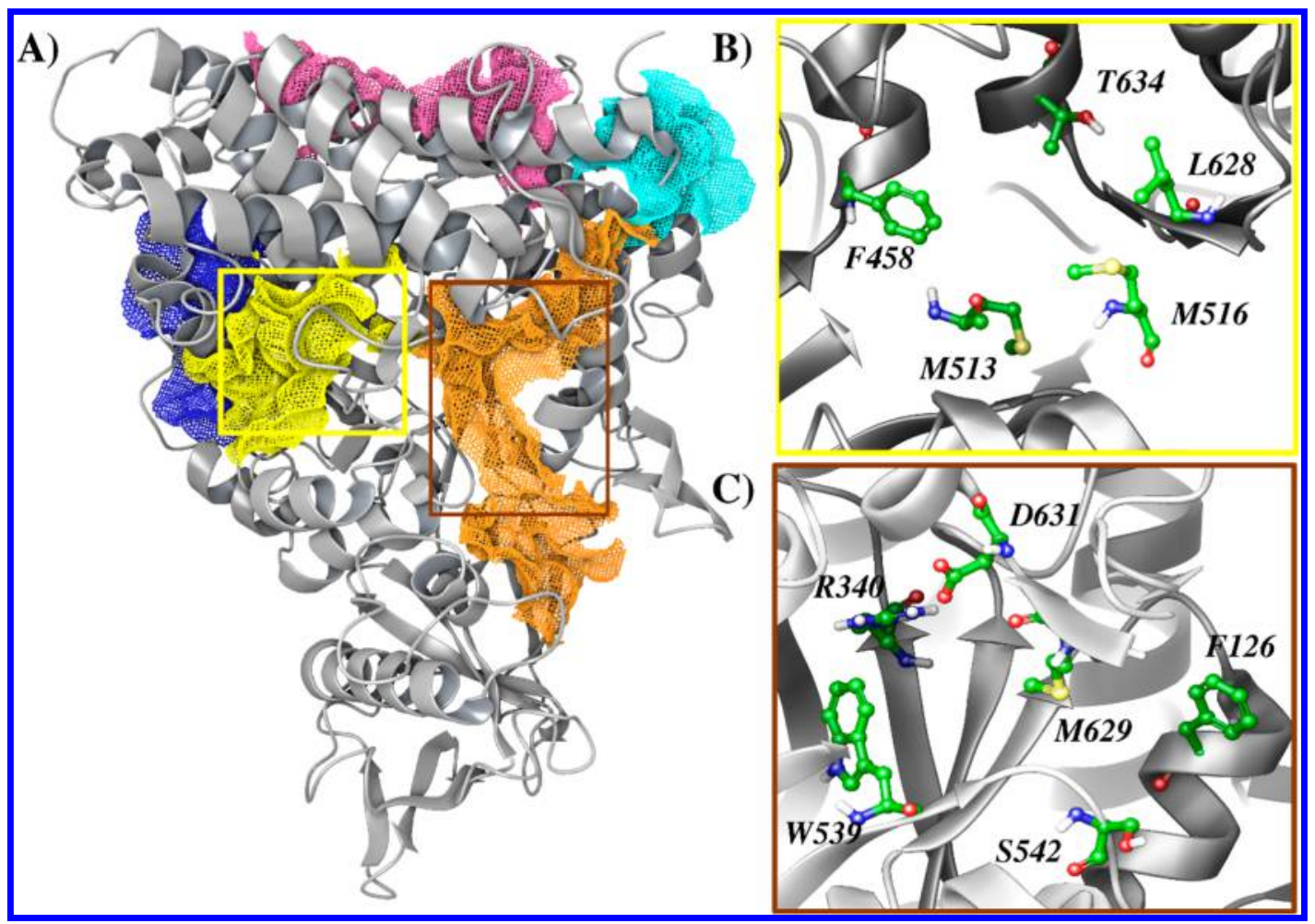

Figure 7. (A) Colored mesh represents the possible binding pockets predicted by SiteMap in P. aeruginosa malate synthase $\mathrm{G}$ (represented as a gray cartoon): site A, yellow; site B, orange; site C, magenta; site D, blue; site E, cyan. Site A is located between a $\beta$-hairpin (amino acids 622-628) in domain II and $\alpha$-helices in the TIM barrel. Site B is composed of loops in the TIM barrel and domains II and III. Site C is located on the edge of the protein between helix $\alpha_{1}$ in the $\mathrm{N}$-terminal region and the final $\alpha$-helix of the protein at the $\mathrm{C}$-terminus, along with a $\beta$-hairpin (amino acids $345-$ 350) from the TIM barrel. Site D is composed of a loop in the N-terminal region and $\alpha$-helices in the TIM barrel. Site E sits near the loops of the Nterminus and C-terminus, and a flexible loop in the TIM barrel. (B) Site A is a hydrophobic pocket, and the binding site residues are shown as sticks. (C) The polar and hydrophobic residues of site B are shown as sticks. These include the Arg340 and Asp631 amino acid side chains involved in catalysis and the active site fluorophore, $\operatorname{Trp} 539$.

overlaps the substrate binding pocket, surrounding the $\beta$ hairpin of domain II (amino acids 615-631), which borders the active site.

Because of the structural conservation and functional significance of sites A and B, we looked for published inhibitors of MS in other organisms that might bind in these sites. To date, however, the few known inhibitors of MS solely target the active site and are either glyoxylate analogues, $\mathrm{Mg}^{2+}$ chelators, or endogenous metabolic intermediates. ${ }^{2,15,26,29,34-36}$

An example of such $\mathrm{Mg}^{2+}$ chelators is a class of compounds, phenyldiketoacids (PDKA), that was discovered to inhibit Mtb MS. ${ }^{4,35,36}$ Mtb MS complexed with the PDKA inhibitors did not show significant conformational changes; however, as seen for ethylene glycol (EDO) in this work, the 1,2-diol moiety in these inhibitors acts as a bidentate ligand of the $\mathrm{Mg}^{2+}$ in the Mtb MS active site. Another example is a study in which a highthroughput screen against PA grown on acetate identified small molecule inhibitors of MS. ${ }^{15}$ In silico binding of these hits following an induced-fit docking procedure to homology models of an Mtb MS crystal structure alluded to a likely interaction with the active site $\mathrm{Mg}^{2+}$.

In a different study of Mtb MS complexed with chemical fragments, 18 fragments that formed a hydrogen bond with the backbone carbonyl of Met631 in the active site were identified. ${ }^{35}$ Met631 (Met629 in PA MS) is conserved in the MS superfamily and is found in site A. The scarcity of PA MS inhibitors highlights the potential of targeting it through alternative binding pockets.

Computational Analysis of Structural Waters. The solvation network in a crystal structure plays an important role in determining protein-ligand binding affinities. Our PA MS crystal structure incorporates 691 water molecules per molecule of MS, as opposed to 450 water molecules per molecule of $\mathrm{Mtb}$ MS (PDB entry 1N8I). However, hydration networks are dynamic, so we used the molecular dynamic simulator, WaterMap, to better understand the possible impact of water molecules on ligand binding. The location of the predicted stable hydration sites was consistent with the observed 


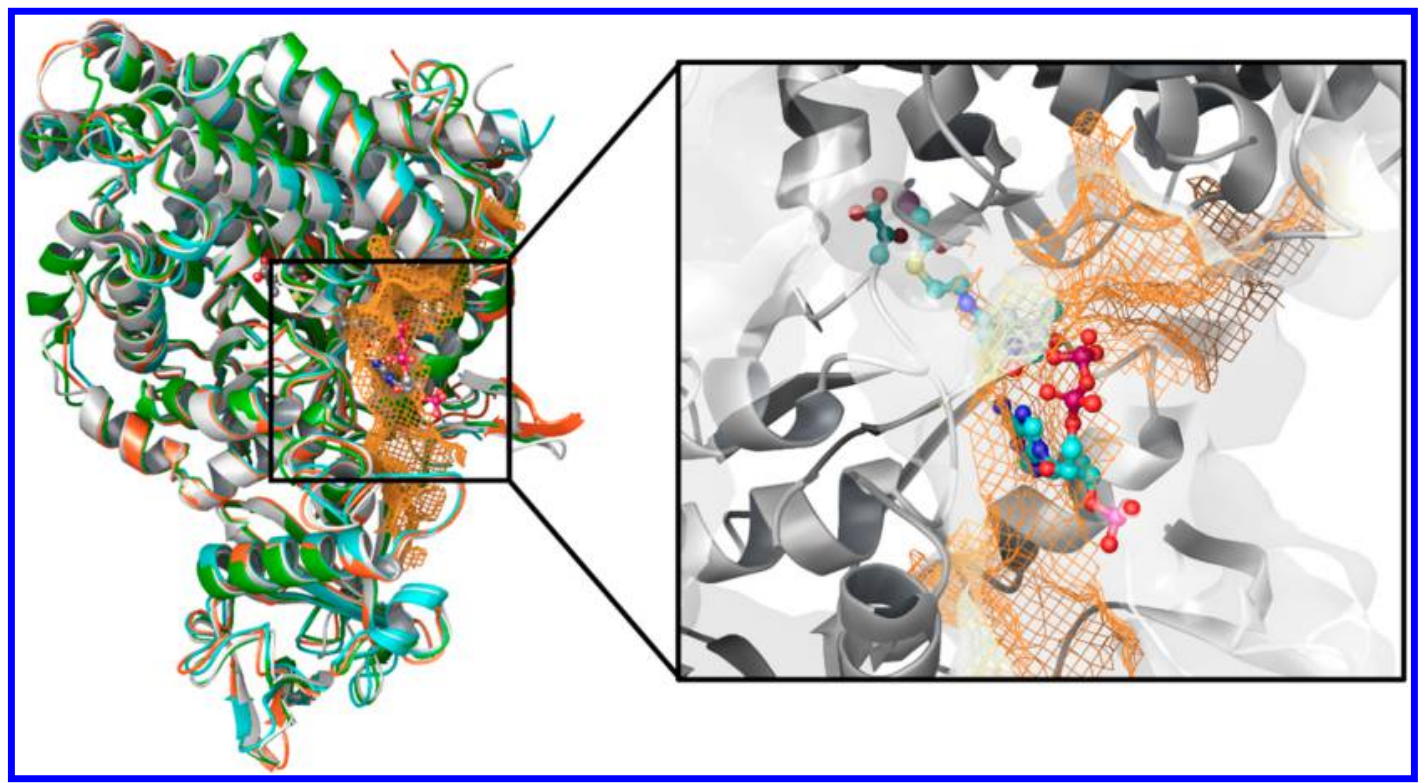

Figure 8. Alignment of malate synthase G crystal structures (gray, P. aeruginosa; green, E. coli; cyan, M. tuberculosis; orange, M. leprae). Predicted binding site $\mathrm{A}$ is shown in orange mesh with substrates glyoxylate and AcCoA (shown as sticks).

crystallographic waters (a snapshot of the active site water molecules is shown in Figure 9).

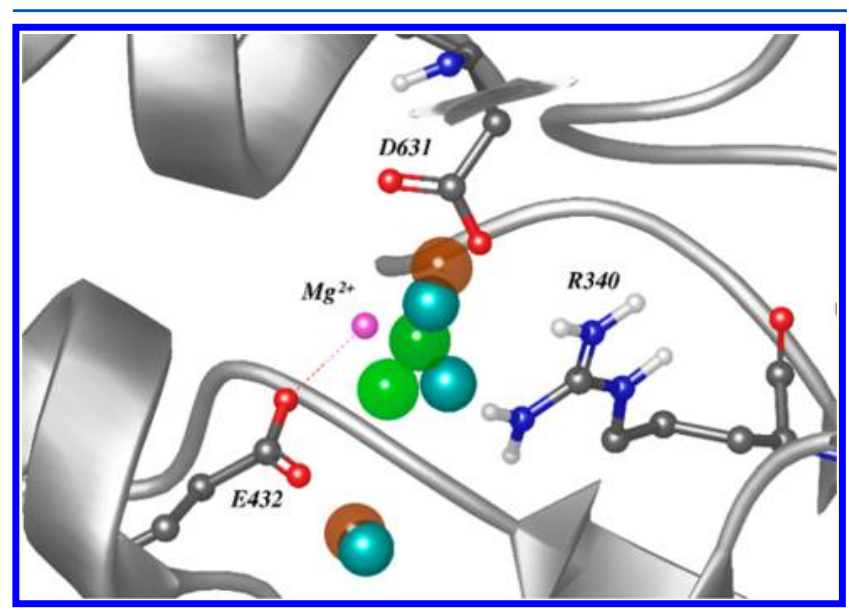

Figure 9. Hydration sites (brown spheres representing unstable water molecules and green spheres representing stable water molecules) predicted by WaterMap superposed with malate synthase $G$ crystal waters (cyan spheres). Catalytic amino acid residues (Arg340, Glu432, and Asp631) are shown as sticks.

The hydration sites predicted by WaterMap gave additional insights into the thermodynamics of the solvation network (Figure 10). The water molecules in the hydration sites colored green are high-energy water molecules. Typically, these water molecules are favorable for binding, and ligands that displace these water molecules must compensate for this free energy loss. Thus, it is better to avoid these sites during ligand design. Conversely, hydration sites colored red/brown portray lowerenergy sites or unfavorable sites. Thus, replacing these water molecules should favor an increase in free energy. WaterMap also predicts cavity regions that are devoid of water molecules, so targeting these regions may help in the search for highaffinity binders.

The WaterMap analysis confirmed the top-ranked predicted binding sites, $\mathrm{A}$ and $\mathrm{B}$ (Table 3), as druggable. WaterMap
(Figure 10A) revealed cavity regions along with unstable hydration sites in sites A (Figure 10B) and B (Figure 10C). The thermodynamic parameters associated with the hydration sites shown in panels B and C of Figure 10 are provided in Table S1. Site B has fewer unstable hydration sites than site A does, which supports the hydrophilic nature of the pocket. In contrast, site A is more hydrophobic. However, the unstable hydration sites in site $\mathrm{A}$ are not continuous, suggesting that a large molecule with several hydrophobic regions would be required to fit in neatly.

One particularly interesting cavity is located near the AcCoA binding site (blue mesh in Figure 10C). This cavity is seen to bind a hydrophobic small molecule [indole-3-carboxylic acid (ICO)] in Mtb MS (PDB entry 5CC5). In that structure, ICO occupies the space between the glyoxylate and AcCoA binding sites (Figure 11), corresponding to the exact cavity identified here in PA MS.

\section{CONCLUSIONS}

The need for new antibacterial agents against $P$. aeruginosa is now critical. Because of the importance of the glyoxylate shunt for persistence in infection scenarios, we have characterized the structure and properties of $P$. aeruginosa malate synthase $G$, with a special emphasis on identifying potential drug binding sites. We report the first X-ray crystal structure of $P$. aeruginosa malate synthase $G$ in the apo form at $1.62 \AA$ resolution. We used the crystal structure to influence experimentation, and we show that events in the enzyme active site can be monitored non-invasively using intrinsic tryptophan fluorescence as a probe. Our computational data reveal two sites in the structure that are promising for drug development as well as the thermodynamic properties of hydration sites within the predicted binding sites. Our findings contribute to the growing body of evidence that malate synthase $G$ is a tractable drug target and provide a means for inhibitor development against $P$. aeruginosa using structure-based approaches. 


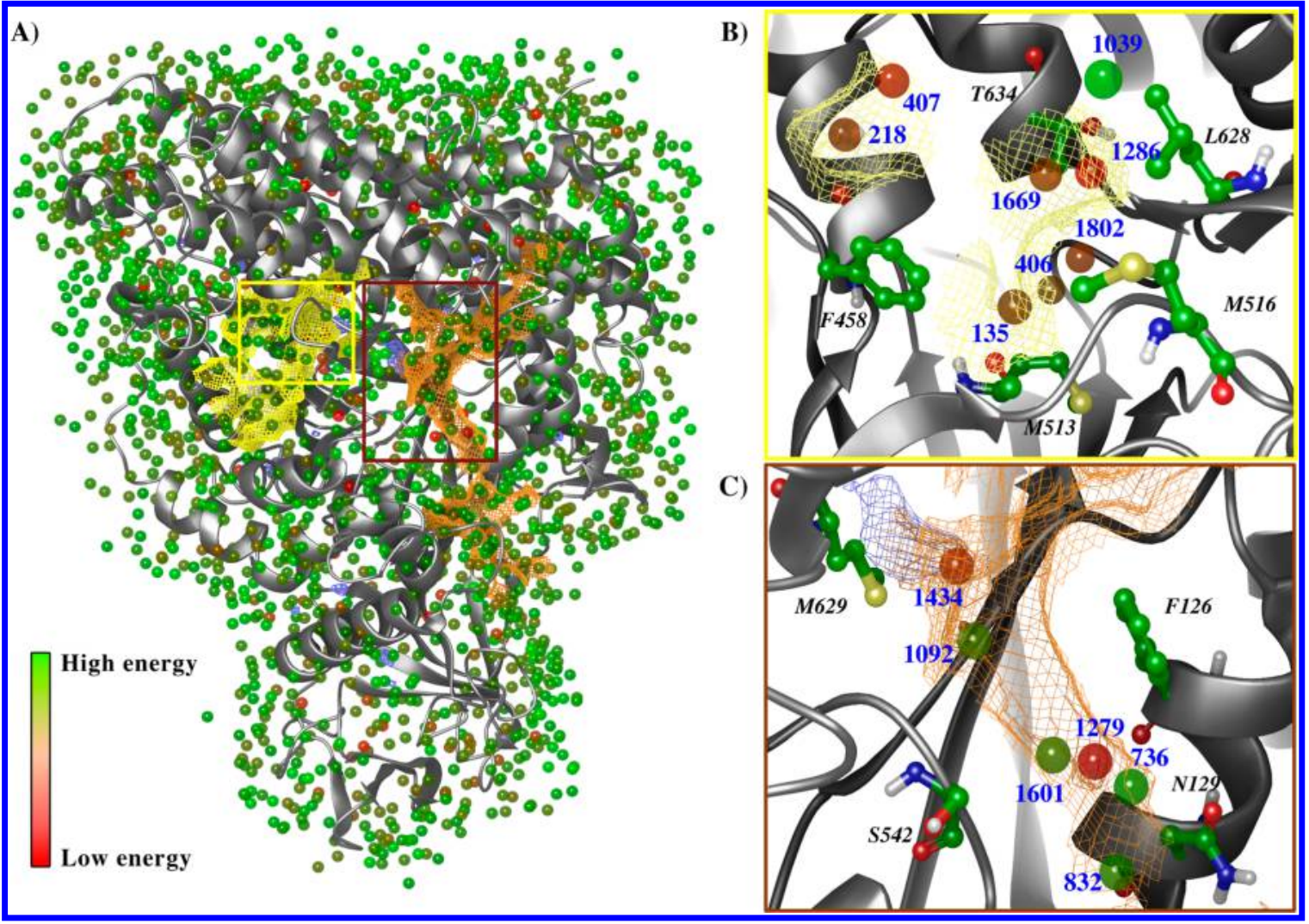

Figure 10. (A) Hydration sites of $P$. aeruginosa malate synthase $G$ along with the cavity map (blue mesh) predicted by WaterMap. The relative free energy of the water molecules is depicted by a green to red color gradient, as indicated. Predicted binding sites A and B are outlined in yellow and brown, respectively. (B) Site A. Yellow surface and active site residues within the site are shown as sticks, and blue labels indicate hydration site numbers. (C) Site B. An orange surface and cavity map (blue mesh) partially occupy the site. The hydrophobic amino acids are shown as sticks, and the hydration sites are labeled in blue.

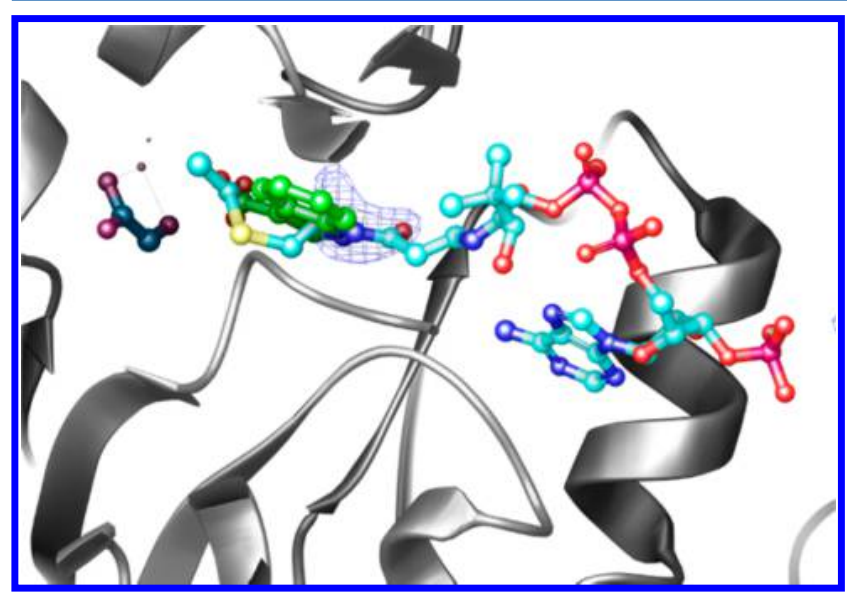

Figure 11. Cavity map predicted by WaterMap (blue mesh). Indole-3carboxylic acid (ICO), which partially occupies the cavity region in $M$. tuberculosis malate synthase G (PDB entry 5CC5), is shown as green sticks. Substrates glyoxylate (teal sticks) and AcCoA (cyan sticks) from PDB entry 1 P7T are also presented to illustrate the binding location.

\section{ASSOCIATED CONTENT}

\section{S Supporting Information}

The Supporting Information is available free of charge on the ACS Publications website at DOI: 10.1021/acs.biochem.7b00852.

Evolutionary tree based on sequence identity of other MSs (Figure S1), sequence alignment of other MSs
(Figure S2), size exclusion chromatography column elution profile of MS (Figure S3), Ramachandran plot (Figure S4), supplemental fluorescence data (Figure S5), $\mathrm{CD}$ data and $\mathrm{CD}$ methods (Figure S6), the general catalytic reaction scheme of MS (Figure S7), and hydration site thermodynamics (Table S1) (PDF)

\section{Accession Codes}

The atomic coordinates and structure factors obtained in this work have been deposited in the PDB as entry 5OAS.

\section{AUTHOR INFORMATION}

\section{Corresponding Author}

*E-mail: mw240@cam.ac.uk. Telephone: +44 (0)1223 333653. ORCID

Alyssa C. McVey: 0000-0001-9284-7652

David R. Spring: 0000-0001-7355-2824

Taufiq Rahman: 0000-0003-3830-5160

\section{Author Contributions}

M.W. conceived the study. A.C.M., P.M., X.C., and S.B. performed experimental work. All authors contributed to the manuscript and have approved the final version.

\section{Funding}

This work was supported by the European Commission's Horizon 2020 Grant 642620 to M.W. and A.P. and BBSRC Grant BB/M019411/1 to M.W.

\section{Notes}

The authors declare no competing financial interest. 


\section{ACKNOWLEDGMENTS}

We thank the Diamond Light Source for access to beamline I03 (proposal MX-14043). We are grateful to Dr. Dima Chirgdaze and Dr. Paul Brear (University of Cambridge) for their assistance with X-ray data collection and analysis.

\section{ABBREVIATIONS}

AcCoA, acetyl-coenzyme A; CoA, coenzyme A; DTNB, 5,5dithiobis(2-nitrobenzoic acid); DTT, dithiothreitol; EDTA, ethylenediaminetetraacetic acid; $G l c B$, malate synthase $\mathrm{G}$ gene; GST, glutathione $S$-transferase; ICL, isocitrate lyase; ICO, indole-3-carboxylic acid; IPTG, isopropyl $\beta$-D-thiogalactopyranoside; MS, malate synthase G; Mtb, M. tuberculosis; ORF, open reading frame; PA, $P$. aeruginosa; PDKA, phenyldiketoacid(s); PDB, Protein Data Bank; PEG, polyethylene glycol; rmsd, root-mean-square deviation; TCEP, tris(2carboxyethyl)phosphine; Tris, tris(hydroxymethyl)aminomethane.

\section{REFERENCES}

(1) Beeckmans, S. (2009) Glyoxylate cycle. In Encyclopedia Microbiology (Schaechter, M., Ed.) 3rd ed., pp 159-179, Elsevier, Oxford, U.K.

(2) Dunn, M. F., Ramírez-Trujillo, J. A., and Hernández-Lucas, I. (2009) Major roles of isocitrate lyase and malate synthase in bacterial and fungal pathogenesis. Microbiology 155, 3166-3175.

(3) Lorenz, M. C., and Fink, G. R. (2002) Life and death in a macrophage: Role of the glyoxylate cycle in virulence. Eukarvotic Cell $1,657-662$.

(4) Myler, P. J., and Stacy, R. (2012) A new drug for an old bug. Chem. Biol. 19, 1499-1500.

(5) Meylan, S., Porter, C. B. M., Yang, J. H., Belenky, P., Gutierrez, A., Lobritz, M. A., Park, J., Kim, S. H., Moskowitz, S. M., and Collins, J. J. (2017) Carbon sources tune antibiotic susceptibility in Pseudomonas aeruginosa via tricarboxylic acid cycle control. Cell Chem. Biol. 24, 195-206.

(6) Tümmler, B., Wiehlmann, L., Klockgether, J., and Cramer, N. (2014) Advances in understanding Pseudomonas. F1000Prime Rep. 6, $1-9$.

(7) Lister, P. D., Wolter, D. J., and Hanson, N. D. (2009) Antibacterial-resistant Pseudomonas aeruginosa: Clinical impact and complex regulation of chromosomally encoded resistance mechanisms. Clin. Microbiol. Rev. 22, 582-610.

(8) Obritsch, M. D., Fish, D. N., MacLaren, R., and Jung, R. (2005) Nosocomial infections due to multidrug-resistant Pseudomonas aeruginosa: Epidemiology and treatment options. Pharmacotherapy 25, 1353-1364.

(9) Son, M. S., Matthews, W. J., Kang, Y., Nguyen, D. T., and Hoang, T. T. (2007) In vivo evidence of Pseudomonas aeruginosa nutrient acquisition and pathogenesis in the lungs of cystic fibrosis patients. Infect. Immun. 75, 5313-5324.

(10) Hogardt, M., and Heesemann, J. (2010) Adaptation of Pseudomonas aeruginosa during persistence in the cystic fibrosis lung. Int. I. Med. Microbiol. 300, 557-562.

(11) World Health Organization (2017) Global priority list of antibiotic-resistant bacteria to guide research, discovery, and development of new antibiotics. http://www.who.int/medicines/publications/ WHO-PPL-Short Summary 25Feb-ET NM WHO.pdf (accessed Aug 11, 2017).

(12) Hagins, J. M., Scoffield, J. A., Suh, S. J., and Silo-Suh, L. (2010) Influence of RpoN on isocitrate lyase activity in Pseudomonas aeruginosa. Microbiology 156, 1201-1210.

(13) Hagins, J. M., Scoffield, J., Suh, S.-J., and Silo-Suh, L. (2011) Malate synthase expression is deregulated in the Pseudomonas aeruginosa cystic fibrosis isolate FRD1. Can. I. Microbiol. 57, 186-95.
(14) Lindsey, T. L., Hagins, J. M., Sokol, P. A., and Silo-Suh, L. A. (2008) Virulence determinants from a cystic fibrosis isolate of Pseudomonas aeruginosa include isocitrate lyase. Microbiology 154, $1616-1627$

(15) Fahnoe, K. C., Flanagan, M. E., Gibson, G., Shanmugasundaram, V., Che, Y., and Tomaras, A. P. (2012) Non-traditional antibacterial screening approaches for the identification of novel inhibitors of the glyoxylate shunt in gram-negative pathogens. PLoS One 7, e51732.

(16) Lucas, X., Bauza, A., Frontera, A., and Quinonero, D. (2016) A thorough anion-pi interaction study in biomolecules: On the importance of cooperativity effects. Chem. Sci. 7, 1038-1050.

(17) Sharma, V., Sharma, S., Hoener zu Bentrup, K., McKinney, J. D., Russell, D. G., Jacobs, W. R., and Sacchettini, J. C. (2000) Structure of isocitrate lyase, a persistence factor of Mycobacterium tuberculosis. Nat. Struct. Biol. 7, 663-668.

(18) Murima, P., McKinney, J. D., and Pethe, K. (2014) Targeting bacterial central metabolism for drug development. Chem. Biol. 21, 1423-1432.

(19) Roucourt, B., Minnebo, N., Augustijns, P., Hertveldt, K., Volckaert, G., and Lavigne, R. (2009) Biochemical characterization of malate synthase G of P. aeruginosa. BMC Biochem. 10, 20.

(20) McCoy, A. J., Grosse-Kunstleve, R. W., Adams, P. D., Winn, M. D., Storoni, L. C., and Read, R. J. (2007) Phaser crystallographic software. I. Appl. Crystallogr. 40, 658-674.

(21) Adams, P. D., Afonine, P. V., Bunkóczi, G., Chen, V. B., Davis, I. W., Echols, N., Headd, J. J., Hung, L. W., Kapral, G. J., GrosseKunstleve, R. W., McCoy, A. J., Moriarty, N. W., Oeffner, R., Read, R. J., Richardson, D. C., Richardson, J. S., Terwilliger, T. C., and Zwart, P. H. (2010) PHENIX: A comprehensive Python-based system for macromolecular structure solution. Acta Crustallogr. Sect. D: Biol. Crystallogr. 66, 213-221.

(22) Emsley, P., and Cowtan, K. (2004) Coot: Model-building tools for molecular graphics. Acta Crustallogr. Sect. D: Biol. Crustallogr. 60, $2126-2132$

(23) Madhavi Sastry, G., Adzhigirey, M., Day, T., Annabhimoju, R., and Sherman, W. (2013) Protein and ligand preparation: Parameters, protocols, and influence on virtual screening enrichments. I. Comput.Aided Mol. Des. 27, 221-234.

(24) Halgren, T. A. (2009) Identifying and characterizing binding sites and assessing druggability. I. Chem. Inf. Model. 49, 377-389.

(25) Abel, R., Young, T., Farid, R., Berne, B. J., and Friesner, R. A. (2008) Role of the active site solvent in the thermodynamics of factor Xa-ligand binding. I. Am. Chem. Soc. 130, 2817-2831.

(26) Smith, C. V., Huang, C. C., Miczak, A., Russell, D. G., Sacchettini, J. C., and Honer zu Bentrup, K. (2003) Biochemical and structural studies of malate synthase from Mycobacterium tuberculosis. I. Biol. Chem. 278, 1735-1743.

(27) Anstrom, D. M., Kallio, K., and Remington, S. J. (2003) Structure of the Escherichia coli malate synthase G: pyruvate: Acetylcoenzyme A abortive ternary complex at $1.95 \AA$ A resolution. Protein Sci. $12,1822-1832$.

(28) Quartararo, C. E., and Blanchard, J. S. (2011) Kinetic and chemical mechanism of the malate synthase from Mycobacterium tuberculosis. Biochemistry 50, 6879-6887.

(29) Reinscheid, D. J., Eikmanns, B. J., and Sahm, H. (1994) Malate synthase from Corynebacterium glutamicum: Sequence analysis of the gene and biochemical characterization of the enzyme. Microbiology 140, 3099-3108.

(30) Goujon, M., McWilliam, H., Li, W., Valentin, F., Squizzato, S., Paern, J., and Lopez, R. (2010) A new bioinformatics analysis tools framework at EMBL-EBI. Nucleic Acids Res. 38, W695-W699.

(31) Sievers, F., Wilm, A., Dineen, D., Gibson, T. J., Karplus, K., Li, W., Lopez, R., McWilliam, H., Remmert, M., Soding, J., Thompson, J. D., and Higgins, D. G. (2011) Fast, scalable generation of high-quality protein multiple sequence alignments using Clustal Omega. Mol. Syst. Biol. 7, 539-539.

(32) Waterhouse, A. M., Procter, J. B., Martin, D. M. A., Clamp, M., and Barton, G. J. (2009) Jalview version 2-A multiple sequence 
alignment editor and analysis workbench. Bioinformatics 25, 11891191.

(33) Anstrom, D. M., Colip, L., Moshofsky, B., Hatcher, E., and Remington, S. J. (2005) Systematic replacement of lysine with glutamine and alanine in Escherichia coli malate synthase G: Effect on crystallization. Acta Crystallogr., Sect. F: Struct. Biol. Cryst. Commun. 61, 1069-1074.

(34) Lohman, J. R., Olson, A. C., and Remington, S. J. (2008) Atomic resolution structures of Escherichia coli and Bacillus anthracis malate synthase A: Comparison with isoform $G$ and implications for structure-based drug discovery. Protein Sci. 17, 1935-1945.

(35) Huang, H., Krieger, I. V., Parai, M. K., Gawandi, V. B., and Sacchettini, J. C. (2016) Mycobacterium tuberculosis malate synthase structures with fragments reveal a portal for substrate/product exchange. I. Biol. Chem. 291, 27421-27432.

(36) Krieger, I. V., Freundlich, J. S., Gawandi, V. B., Roberts, J. P., Gawandi, V. B., Sun, Q., Owen, J. L., Fraile, M. T., Huss, S. I., Lavandera, J. L., Ioerger, T. R., and Sacchettini, J. C. (2012) Structureguided discovery of phenyl-diketo acids as potent inhibitors of $\mathrm{M}$. tuberculosis malate synthase. Chem. Biol. 19, 1556-1567.

(37) Bauzá, A., Quiñonero, D., Deyà, P. M., and Frontera, A. (2014) Long-range effects in anion- $\pi$ interactions: Their crucial role in the inhibition mechanism of Mycobacterium tuberculosis malate synthase. Chem. - Eur. I. 20, 6985-6990.

(38) Howard, B. R., Endrizzi, J. A., and Remington, S. J. (2000) Crystal structure of Escherichia coli malate synthase G complexed with magnesium and glyoxylate at $2.0 \AA$ resolution: Mechanistic implications. Biochemistry 39, 3156-3168.

(39) Anstrom, D. M., and Remington, S. J. (2006) The product complex of M. tuberculosis malate synthase revisited. Protein Sci. 15, 2002-2007.

(40) Beeckmans, S., Khan, A. S., Kanarek, L., and Van Driessche, E. (1994) Ligand binding on to maize (Zea mays) malate sythase: A structural study. Biochem. I. 303, 413-421.

(41) Lukat, G. S., Stock, A. M., and Stock, J. B. (1990) Divalent metal ion binding to the $\mathrm{CheY}$ protein and its significance to phosphotransfer in bacterial chemotaxis. Biochemistry 29, 5436-5442. 